\title{
A ucuuba de várzea e suas aplicações (")
}

\author{
WILliam A. RODRIgues (**) \\ Instituto Nacional de Pesquisas \\ da Amazônia
}

\section{SINOPSE}

Trata este trabalho principalmente do estudo botânico, silvicultural e tecnológico de uma essência de grandes possibilidades comerciais, conhecida na Amazônia brasileira por "ucuuba de várzea" (Virula surinamensis (Rol.) Warb.).

\section{INTRODUÇÃo}

"Ucuuba" é uma denominação tupi que se aplica vulgarmente na Amazônia brasileira à maioria das espécies do gênero botânico Virola, significando "árvore que produz substância gordurosa". Etimologicamente, é formada dos vocábulos "uku" (gordura, graxa, sebo) e "uba" (árvore, planta). Apesar da generalização do nome vernacular, o presente trabalho se refere em especial à "ucuuba de várzea" Virola surinamensis (Rol.) Warb.).

As ucuubas em sua totalidade pertencem à família das Myristicaceae, a qual, de acordo com o sistema de classificação de Hutchinson (1960), integra a ordem das Laurales juntamente com as seguintes famílias da América:

\section{1) Monimiaceae \\ 2) Lauraceae \\ 3) Gomortegaceae \\ 4) Hernandiaceae}

Segundo Warburg (1897) e Smith (1937). no continente americano existem 5 gêneros botânicos nativos de Miristicáceas :
1) Compsoneura Warb.
2) Dialyanthera Warb.
3) Iryanthera Warb.
4) Osteophloem Warb.
5) Virola Warb.

Na América, o centro de dispersão da família é a Amazônia. Todos os gêneros antes citados têm a maioria de suas espécies na Hiléia, chegando mesmo alguns deles a serem endêmicos dessa região, como os gêneros Iryanthera e Osteophloem. Existe também no continente americano o gênero exótico Myristica L., o qual é representado pela "noz mosca. da" (Myristica fragrans Houtt.), úrica espécie do gênero que se cultiva neste continente.

O gênero "Virola"

O nome botânico criado por Aublet em 1775 para a denominação científica das ucuubas foi tirado do nome vernacular da espécie-tipo ( $\mathrm{V}$ rola sebifera Aubl.), com que os nativos Galibis da Guiana Francesa conheciam essa espécie. Atualmente, chega a 45 o número de espécies de Virola cientificamente aceito para toda a América, sendo que desse total 30 săo exclusivamente da bacia amazônica.

Smith (1937) dividiu o gênero Virola em 6 grupos ou secções, ficando Virola surinamensis (Rol). Warb. na secção Surinamensis juntamente com:

$$
\begin{aligned}
& \text { V. oleifera (Schott) A.C. Smith } \\
& \text { V. nobilis A.C. Smith } \\
& \text { V. glaziovii Warb. } \\
& \text { V. carinata (Bth.) Warb. } \\
& \text { V. gardneri (A. DC.) Warb. } \\
& \text { V. malmei A.C. Smith } \\
& \text { V. parvifolia Ducke } \\
& \text { V. guatemalensis (Hemsl.) Warb. } \\
& \text { V. multiflora (Standl.) A.C. Smith } \\
& \text { V. venosa (Bth.) Warb. } \\
& \text { V. melinonii (Ben.) A.C. Smith } \\
& \text { V. pavonis (A. DC.) A.C. Smith } \\
& \text { V. weberbaueri Markgraf }
\end{aligned}
$$

(*) - Trabalho executado graças a uma bolsa da John Simon Guggenheim Memorial Foundation e apresentado no Simpósio Internacional sobre Plantas da Flora Amazônica, Belém, 1972.

$(* *)$ - Bolsista do Conselho Nacional de Pesquisas. 
A maior afinidade da espécie em estudo é com $V$. nobilis do Panamá e com as essências amazônicas $V$. carinata e $V$. pavonis, das quais se distingue especialmente pelos seguintes caracteres do fruto, exposto na chave sinóptica abaixo :

1 - Fruto até $32 \mathrm{~mm}$ de comprimento por $22 \mathrm{~mm}$ de larg., distintamente estipado na base, o pericarpo de $1,5-3 \mathrm{~mm}$ de espessura, obtuso no ápice, não carenado ..........

V. nobilis

2 - Sem esses caracteres.

3

3 - Fruto até $21 \mathrm{~mm}$ de compr. $18 \mathrm{~mm}$ de larg. inconspicuamente estipi$\mathrm{t} a \mathrm{do}$, pericarpo de $1-2 \mathrm{~mm}$ de espessura, muitas vezes apiculado no ápice, carenado ...V. surinamensis

4 - sem esses caracteres

5

5 - Fruto subgloboso até $25 \mathrm{~mm}$ de diâmetro, liso ou levemente impresso nas suturas, arredondado no ápice. pericarpo até $4 \mathrm{~mm}$ de espessura

6 - Fruto elipsoide até $50 \mathrm{~mm}$ de compr. por $22 \mathrm{~mm}$ de larg., em geral distintamente carenado, ápice obtuso ou subagudo, pericarpo lenhoso até $7 \mathrm{~mm}$ de espessura .............

V. pavonis

DADOS BOTÂNICOS DA UCUUBA DE VÁRZEA

a) Denominação científica

Virola surinamensis (Rol.) Warb.

b) Sinonímia botânica :

Myristica surinamensis Rolander

Myristica fatua Swartz

Myristica angustifolia Lamarck

Myristica sebifera Aubl. var. longifolia Lam.

Nux moschata silvestres surinamensis Jac. Breyn.

Virola mycetis Pulle c) Denominações vulgares :

Brasil : ucuuba, u. da várzea, u. brarı. ca, bicuíba (Amazônia); andiroba (Ceará).

Guiana: dalli, dalliba, white dalli.

Guiana Francesa: guingumadou, guinguamadou de montagne, yayamadou, $y$. de marècage, jea ou jeamadou, moulamba, virola, moussigot, bali, dalli, arbre à suif.

Suriname : bambien, bamboentrie, baboenhoedos, baboenhout, baboun houdou, mooba, daliie, waroesie, moschatboom.

Peru: cumala

Venezuela: camaticaro, cuajo

Honduras : banak

Guadalupe : muscadier fou

Granada e Trinidad: wild nutmeg

Trinidad : cajuca

Espanhóis: muscade de Pará, cova longa.

d) Nomes comerciais :

Banak ou Virola

\section{DESCRIÇÃO BOTÂNICA (Fig. 1)}

Árvore até $30 \mathrm{~m}$ de altura e pouco mais de $1 \mathrm{~m}$ de diâmetro de tronco, copa pequena, pouco ramificada, ramificação verticilada, quase horizontai, casca castanho-amarelada com partes acinzentadas, e esbranquiçadas, lisa, ligeiramente enrugada e estriada no sentido vertical, um pouco quebradiça, muito aderente, instilando por incisão um líquido transparente; ramos densamente foliosos, quando jovens flexuosos, verdes, glabros, de ápice finamente pubescente; folhas curto-pecioladas, alternas; pecíolo fortemente caniculado, tomentelo ou glabro; lâmina foliar coriácea, estreitamente oblonga, de margem um tanto paralela, de $10-25 \mathrm{~cm}$ de compr., $2-5 \mathrm{~cm}$ de larg., subcordada, arredondada, obtusa ou aguda na base, cuspidada, aguda ou curtoacuminada no ápice, na página inferior pálidopuberulenta (pelos sessil-estrelados), nervura mediana plana ou ligeiramente imersa na página superior, saliente na pág. inferior, 16-30 nervuras secundárias por lado, planas ou ligeiramente impressas na pág. superior, bem elevadas na inferior, sub-horizontais, arqueadas, sol- 


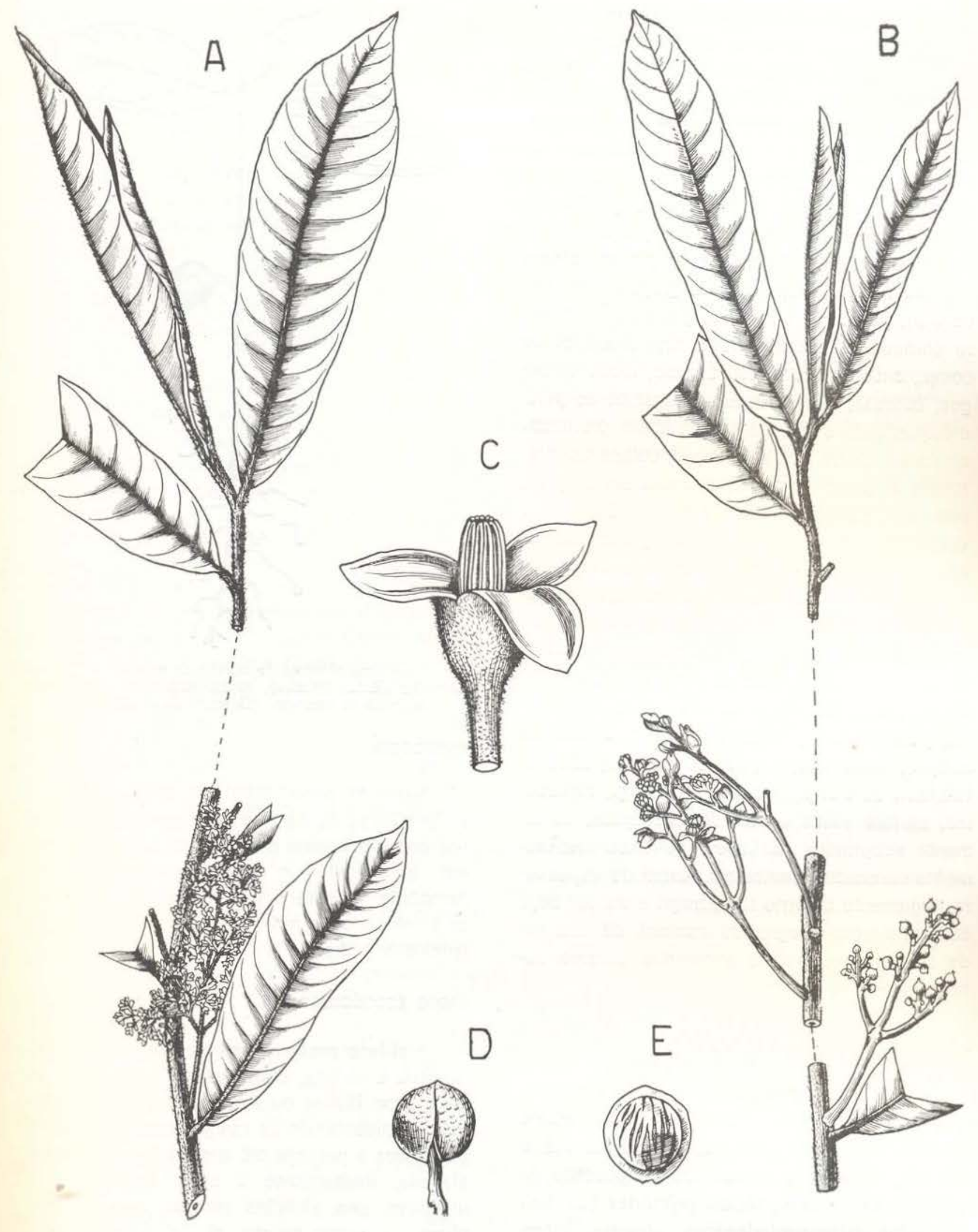

Fig. 1 - Ucuuba de várzea (Virola surinamensis (Rol.) Warb.) - A, raminho com inflorescência masculina; B, raminho com inflorescência feminina; C, flor masculina; D, fruto; E, uma seç̧ão do fruto mostrando parte da semente e arilo. 
dando-se à pouca distância da margem, vênulas obscuras ou ligeiramente impressas em ambas as superfícies; inflorescência masculina largamente paniculada, um tanto densa, livremente ramificada, pedúnculo com frequência ligeiramente achatado, pedicelos e flores áureo ou cinéreo-puberulentos (pelos séssil-estrelados), pontas dos pendúncuios distalmente engrossadas; bracteas oblongas, $3-8 \mathrm{~mm}$ de compr. puberulen. tas, distintas nas inflorescëncias jovens, depois deciduas; tlores dispostas em grupos termınaıs de $5-20$, pedicelos aeigados; perianto levemente carnoso ou submembranáceo, $1,6-2,4 \mathrm{~mm}$ de comp., 3-lobato até quase à base, lobos oblongos, obtusos, muitas vezes esparsamente pelúcido-punctado e as vezes com veias distintas: anaroceu 1,3-1,9 mm de compr., coluna do filamento delgada, 3 anteras, soldadas até o ápice, obtusas; intlorescencia teminina $2-8 \mathrm{~cm}$ de compr., na antese, 3-6 tlores por grupo, pedicelos curtos, bracteas como nas intıorescencias masculinas; ovário subgloboso, densamente puberulento, estilete grosso, estigma brilhante, profundamente partido, inflorescencias frutíteras essencialmente glabras por inteiro, $6-11 \mathrm{~cm}$ de compr., frutos maduros 3.8 por intlorescência, pedicelados (pedicelos grossos, $3-7 \mathrm{~mm}$ de compr.), coriàceos, elipsóides ou subglobosos, $13-21 \mathrm{~mm}$ de compr., 11-18mm de larg., deiscentes, muitas vezes apiculados no ápice, curta. mente estipitados na base, ligeira ou distintamente carenados, pericarpo $1-2 \mathrm{~mm}$ de espessura, tegumento externo fino, frágil e de côr beje escura, interno enegrecido marcado de uma rede de fibras vermelhas achatadas, albume esbranquiçado, ruminado.

\section{DESCRIÇÃo DA PLÂNTULA (Fig. 2)}

Plântula de germinação criptocotiledonar, epígea, dicotiledonar, os cotilédones bem acima do solo envolvidos pelo espermoderma até o seu desprendimento, separando o hipocótilo do epicótilo, peciolados; folhas primárias (eófilas) pecioladas, supracotiledonares, simples, alternadas, conduplicadas, estipuladas, inteiras, glabras, peninérveas, nervuras broquidódromas.

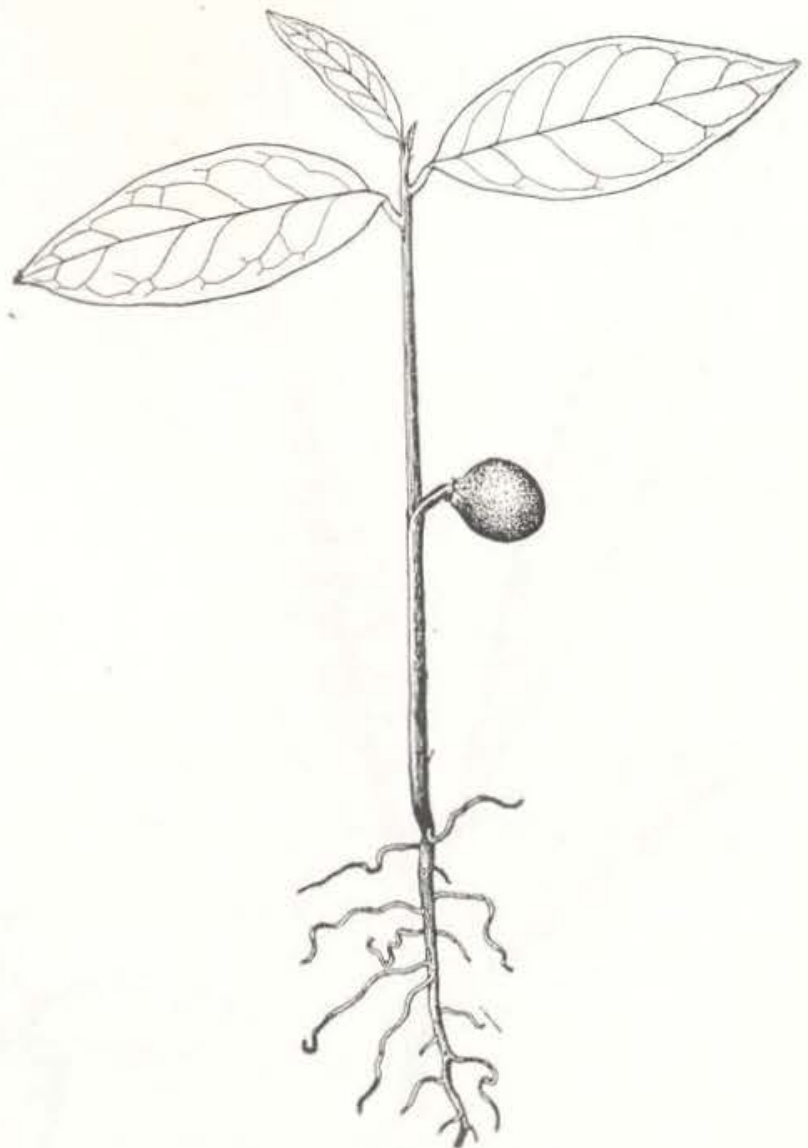

Fig. 2 - Uma plântula de ucuuba de várzea (Virola surinamensis (Rol.) Warb.), recém-germinada, ainda ligada ao resto de semente. (Desenho de J. Dellome)

\section{FENOLOGIA}

Segundo Bena (1960), na Guiana Francesa a floração se dá durante pelo menos duas vezes por ano, em março e setembro e a frutificaçäo em maio-junho e novembro-dezembro. $\mathrm{Na}$ Amazônia brasileira a floração vai de agos to a princípio de novembro e a frutificação, de janeiro a julho.

\section{DADOS ECOLÓGICOS}

Prolifera preferentemente nos lugares pantanosos e férteis, ilhas baixas e em quase to. da a zona fluvial do Amazonas e seus afluentes, acompanhando as margens dos rios, igarapés, furos e paranás até onde a terra possa ser alagada, limitando-se à mata periodicamente inundável dos aluviōes recentes que acompanham os cursos de rios de água rica de sedimentos (água branca). Não ocorre em geral nos rios de água preta (com exceção do baixo 
rio Negro), sendo ai substituida pelas vicariantes $V$. carinata e $V$. pavonis. É uma essência heliófila. Ocorre em geral associada com o anani (Symphonia globulifera L.f.) .

\section{DISTRIBUIÇÃO GEOGRÁFICA}

Espécie de larga distribuição desde as Antilhas Menores (Guadalupe e Granada), Tabago. Trinidad, Guianas, Venezuela meridional, Bolívia até o Brasil. Neste ocorre em quase toda área amazônica (Territórios do Amapá, Roraima e Rondônia, e Estados do Pará e Amazonas) e no nordeste desde Maranhão até perto de Recife, Pernambuco.

Segundo Ducke (1945) a ucuuba é extrema. mente abundante nas ilhas baixas do grande estuário amazônico, inundáveis pela maré do Atlântico, constituindo em algumas dessas ithas a maioria das árvores de até $20 \mathrm{~m}$ de altura.

\section{ABUNDÂNCIA}

Uma avaliaçăo mais precisa da abundância de uma essência numa regiáo em geral se faz através de levantamentos florestais. Para a ucuuba estes dados se podem obter especi- almente em Pires \& Koury (1959), Glerum (1962), Heinsdijik \& Bastos (1963) e Glerum \& Smit (1965) para a Amazônia brasileira e em de Milde \& Groot (1970) para a Guiana

De todos os dados disponiveis o mais importante é o de Glerum (1962) por ter sido feito exclusivamente com o objetivo de avaliar o potencial econômico da ucuuba nas matas de várzea do Baixo Tocantins, uma das áreas de maior ocorrência conhecida da espécie da bacia amazônica. Os resultados que apresenta se baseiam em apenas um inventário, não se po. dendo portanto generalizar para toda a regiau de varzea onde e sabido haver a especie.

A área do inventário realizado por Glerum no Baixo Tocantins totalizou cerca de 150000 hectares, abrangendo as seguintes regióes:

1 - Faixa entre Tucuruí e Baião com um total de cerca de 85000 hectares.

II - Ilhas ao norte de Baião com total de aproximadamente $50000 \mathrm{Ha}$.

III - Margens do rio Anapu e afluentes com um total de 10000 a $15000 \mathrm{Ha}$.

Os resultados desse inventário encontramse resumidos no Quadro abaixo.

\section{QUADRO I}

Inventário florestal da ocorrência de ucuuba na área do Baixo Tocantins, Pará. As classes de diâmetro $1,2,3,4$ e 5 correspondem respectivamente aos seguintes diâmetros de fuste: $1(5-14 \mathrm{~cm}) ; 2(15-24 \mathrm{~cm})$; $3(25-34 \mathrm{~cm}) ; 4(35-44 \mathrm{~cm})$, e $5(45-54 \mathrm{~cm})$. Dados extraídos de Glerum (1962).

\begin{tabular}{|c|c|c|c|c|c|c|c|c|c|c|}
\hline \multirow{3}{*}{ REGIÃO } & \multicolumn{5}{|c|}{ № de árvores } & \multicolumn{5}{|c|}{ Volume de madeira $(*)$} \\
\hline & \multicolumn{5}{|c|}{ Classe do diâmetro } & \multicolumn{5}{|c|}{ Classe do diâmetro } \\
\hline & 1 & 2 & 3 & 4 & 5 & 1 & 2 & 3 & 4 & 5 \\
\hline Tucuruí-Baião & 0,7 & 0,9 & 0,4 & 0,2 & 0,3 & - & -. & 0,3 & 0,3 & 0,8 \\
\hline Ilhas ao norte de Baiăo & 12,9 & 12,4 & 12,7 & 9,6 & 7,2 & - & - & 7,7 & 12,1 & 19,0 \\
\hline Rio Anapu e afiuentes & 5,0 & 4,3 & 3,1 & 1,7 & 0,6 & - & - & 2,1 & 2,2 & 1,3 \\
\hline
\end{tabular}

( $)$ - Volume de madeira sem casca. 
Das regiōes inventariadas, conforme o Quadro 1 anexo, a das ilhas ao norte do Baião foi a que apresentou resultados significativamente maiores em todas as classes de diâmetro, não só no número de árvores como no volume de madeira por hectare. Segundo Glerum, para essa região toda podia-se estimar com certa reserva a cubagem total de madeira sem casca a partir da classe 3 para cima em $1745000 \mathrm{~m}^{3}$ e a de classes 5 e acima em $855000 \mathrm{~m}^{3}$.

Num inventário realizado por Pires \& Koury (1959) numa área de várzea perto de Belem, Pará, onde todas as plantas abaixo de 5 a $8 \mathrm{~cm}$ de diâmetro toram desprezadas, num hectare foi assinalada a presença de 8 ucuubeiras, com um volume da madeira comercial de $10,528 \mathrm{~m}^{3}$ e uma cubagem total de $12,133 \mathrm{~m}^{3}$, incluindo a gaiharia.

Numa outra área estudada pelos mesmos autores acima citados, tomanco por base dessa vez $3,8 \mathrm{Ha}$. de mata de várzea, em que foram levadas em consideraçăo apenas as árvores de $10 \mathrm{~cm}$ e mais de diâmetro, foram encontradas por hectare 9,2 ucuubeiras acima de $10 \mathrm{~cm}$ de diâmetro e 3,9 acima de $40 \mathrm{~cm}$. Neste caso a cubagem de madeira não foi avaliada. A presença da espécie em relação ao número total de parcelas de $10 \times 100 \mathrm{~m}$ foi de $42 \%$ e sua frequência em relação ao total de indivíduos cie outras espécies encontradas associadas com ela foi de $1,9 \%$, porcentagem esta relativamen. te baixa, se comparada com outras espécies coexistentes com ela na mesma comunidade, tais como :

\begin{tabular}{|c|c|c|}
\hline & $\begin{array}{c}\text { Freqüência } \\
\%\end{array}$ & $\begin{array}{c}\text { Presença } \\
\%\end{array}$ \\
\hline Açaí (Euterpe oleracea Mart.) & 16,38 & 100,00 \\
\hline $\begin{array}{l}\text { Murumuru (Astrocaryum murumuru } \\
\text { Mart.) }\end{array}$ & 13,49 & 94,74 \\
\hline $\begin{array}{l}\text { Ingarana (Pithecolobium latifolium } \\
\text { (L.) Bth.) }\end{array}$ & 7,56 & 84,21 \\
\hline Andiroba (Carapa guianensis Aubl.) & 6,15 & 94,74 \\
\hline $\begin{array}{l}\text { Inajarana (Quararibea guianensis } \\
\text { Aubl.) }\end{array}$ & 5,60 & 84,21 \\
\hline Açacu (Hura crepitans L.) & 4,19 & 71,05 \\
\hline $\begin{array}{l}\text { Pracaxi (Pentaclothra macroloba } \\
\text { (Willd.) Katze.) }\end{array}$ & 3,32 & 76,32 \\
\hline
\end{tabular}

Em relação aos inventários anteriormente referidos, a mata da Guiana é consideravelmente mais pobre em ucuuba que a do estuário amazônico. De Milde \& Groot (1970) estimam em 1,98 o número de árvores por hectare da referida espécie de $30 \mathrm{~cm}$ e mais de diâmetro no Distrito Noroeste daquele País onde foi feita. por eles, uma prospecção.

Segundo Glerum (1962), as principais palmeiras que vivem associadas com a ucuuba na região do Baixo Tocantins são buriti (Mauritia flexuosa L.f.), açaí (Euterpe oleracea Mart.). e ubuçu (Manicaria saccifera Gaertn.), especialmente a primeira, segundo ele, cuja presença é geralmente indicaçăo certa também de ucuuba. Na Guiana, baseando-se na prospecção de De Milde \& Groot (1970), as principais espécies em geral associadas com a ucuuba são a Symphonia globulifera e a Tabebuia insignis var. macrophylla.

\section{DADOS SILVICULTURAIS}

Ouase nada se conhece até hoje sôbre o plantio de ucuuba quer em escala experimental ou de reflorestamento com vista a suprir racionalmente as indústrias de transformação e beneficiamento de matéria prima suficiente às suas demandas da essência em questão. Aliâs o mesmo se pode afirmar para a maioria das essências de idêntico valor econômico da Hiléia. Lamentavelmente ainda predomina nessa regiãc o extrativismo contumaz, muito embora o govêrno acertadamente venha pondo cobro a tudo isso através de leis que mais servem de incentivo que de desestímulo e proibição.

Segundo se sabe a ucuuba de várzea é uma essência heliófila de crescimento rápido. No Jardim Botânico do Rio de Janeiro, conforme Campos Porto (1936), foram introduzidas algumas árvores em 1923, as quais se apresentavam robustas e frutificavam abundantemente. Nos terrenos do Instituto de Pesquisas e Experimentação Agropecuárias do Norte, em Belém, Pará, foram plantadas em março de 19674 linhas de ucuuba na terra firme em solo concrecionário com o espaçamento de $3 \times 1 \mathrm{~m}$. Devido talvez ao tipo de solo ou habitat impróprio, as plantas estavam com crescimento um tanto lento, 
atingindo os espécimes de maior porte cerca de $5 \mathrm{~m}$ de altura. Sanitariamente, aparentavam bom aspecto.

Este ano (1972) a firma Standard Norte Reflorestamento Ltda., sediada em Belém, está iniciando o projeto de plantio de 500 hectares de ucuuba na várzea alta da localidade de Breves, segundo informações dos Drs. José Maria Conduru e Edgar Menezes.

Estắo iniciando o plantio com a adoção do seguinte método :

Propagação: por semente. Como estas perdem a vitalidade muito rapidamente (depois de 15 a 20 dias), o semeio em geral é feito logo após a sua colheita. Por este processo a germinação chega a quase $100 \%$, aparecendo as primeiras mudinhas após 28 dias de semeadas.

Plantio: após 60 dias, quando atingem 40 $\mathrm{cm}$ de altura, as mudinhas são transplantadas para 0 local definitivo com raizes ruas. A pega neste caso chega a quase $90 \%$. O espaçamento adotado é de $2 \times 2$. Dubois (1967) sugere dois métodos silviculturais para o seu plantio.

1) método de uniformização

2) método do plantio agro-florestal

1) Método de uniformização - Consiste na eliminação mais ou menos progressiva das árvores sem valor a fim de permitir um melhor e mais rápido crescimento das espécies desejáveis. Este método se aplica em mata destituida de potencial suficiente para exportação comercial imediata, onde boas espécies que se podem utilizar na indústria estejam bem representadas em classe de diâmetro médio. A eliminação progressiva dos elementos indesejáveis dá maior espaço vital às árvores de valor que se desejam incrementar de maneira a permitir que estas atinjam a maturidade comercial muito mais rapidamente do que se a mata original fosse deixada entregue ao acaso.

A aplicabilidade deste método estava sendo esłudada em Curuá-Una, Pará, pelo Serviço de Treinamento e Pesquisas Florestais-Santarém visando em especial a um povoamento pauciespecífico com dominância principalmente de ucuuba num facies jovem de mata de várzea.
2) Método agro-florestal - Trata êste mé. todo em plantar essências comerciais como a ucuuba, com espaçamento uniforme durante a rotação agrícola ou em associação com culturas anuais. Este método tem sido usado com grande êxito no desenvolvimento da economia florestal de muitos países tropicais, onde a agricultura nômade é tradicional. Tais práticas, segundo Dubois, podem ter notáveis possibilidades de aplicação na Amazônia principalmente em conexão com os planos de colonização rural do tipo cooperativista. Com relação à ucuuba, o seu plantio deveria ser tentado em terras de várzea associada, por exemplo, com a rotaçāo juta-feijão.

Os histogramas da distribuiçăo natural dos diâmetros de ucuuba apresentados por Heinsdijk \& Bastos (1963) e De Milde \& Groot (1970) e neste trabalho reproduzidos (figs. 3 e 4), são mais ou menos iguais e mostram que a ucuuba tem um crescimento muito vagaroso até a classe de diámetro $3(25-34 \mathrm{~cm}$ de diâmetro no histograma de Heinsdijk \& Bastos e $36-39 \mathrm{~cm}$, no de De Milde \& Groot), depois, então, se torna regular, indicando que, sendo espécie heliófila, ao se ver forçada a se desenvolver à sombra de outras concorrentes, cresce devagar, só de-pois que consegue vencer a concorrência e re-

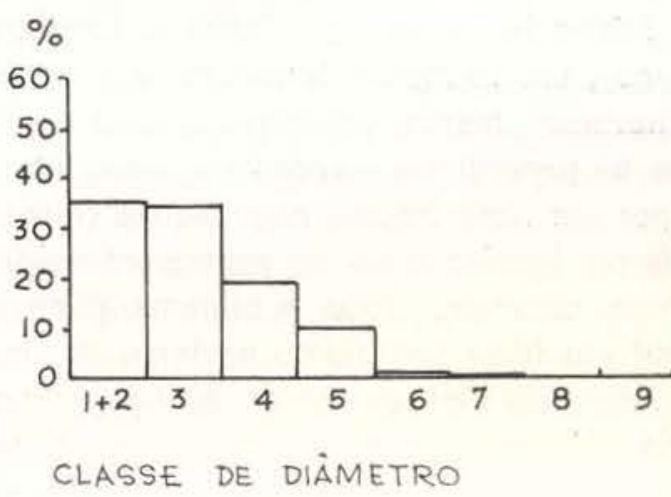

Fig. 3- Histograma de distribuiçẫo das árvores de ucuuba (Virola surinamensis (Rol.) Warb.) na Amazônia Brasileira segundo as classes de diâmetro

(Cópia extraída de Heinsdijk \& Bastos, 1963).

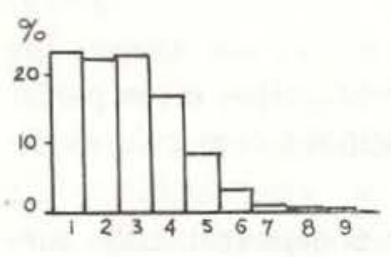

CLASSE dE DIAMMETRO
Fig. 4 - Histograma de distribuição das árvores de ucuuba (Virola surinamensis (Rol.) Warb.). na Guiana segundo as classes de diâme. tro. (Cópia extraída de Milde \& Groot, 1970). 
ceber iluminação razoável é que passa a ter incremento normal até a morte em decorrência do fim do seu ciclo vital.

Sobre a sua regeneração natural também quase nada se sabe. Pires \& Koury (1959) numa pequena observação realizada em área de várzea do Guamá perto de Belém, Pará, onde $1 \mathrm{Ha}$ de sua mata original havia sido derrubado tempos atrás, verificaram que $25 \%$ das ucuubas cortadas brotavam de toco.

\section{Fitopatologia}

Dados a este respeito não säo ainda conhecidos. Melo et al. (1971) cita no entanto que análises em algumas folhas de ucuuba de várzea que apresentavam formações rugosas e de côr rósea na superfcie inferior das mesmas mostravam-se levemente atacadas de um fungo imperfeito (Aschersonia aleyrodes) entomófago, de ocorrência comum em plantas cítricas, que parasita insetos Aleyrodideos.

\section{HISTOLOGIA DA FOLHA}

Estudo a respeito apresenta Martin-Lavigne (1909). (Fig. 5)

A nervura mediana é saliente na página inferior da folha e ligeiramente côncava na superior. O sistema líbero-lenhoso é constituido de 2 feixes lenhosos: o inferior é fortemente arqueado, em forma de ferradura, e o superior é transversal, menor, unido pelas duas extremidades ao precedente. Todos os 2 são envolvidos por um liber frouxo, com alguns feixes do periderme ligados mais ou menos intimamente ao feixe superior. Todo o sistema é envolvido por um feixe pericíclico esclerosado, contínuo, com exceção nos pontos de ligação dos 2 feixes. Na margem do limbo foliar, o sistema fascicular da nervura é reduzido ao feixe grande inferior e a alguns isolados da parte superior No tecido perifascicular, distinguem-se volumosas grândulas unicelulares.

O mesófilo é bifacial com uma só camada de células palissádicas, que ocupa apenas um terço da espessura do limbo foliar, e um parêli quima mais ou menos lacunoso com células secretoras esparsas.

A epiderme superior é espessamente cutinizada e constituida de pequenas células de pa-

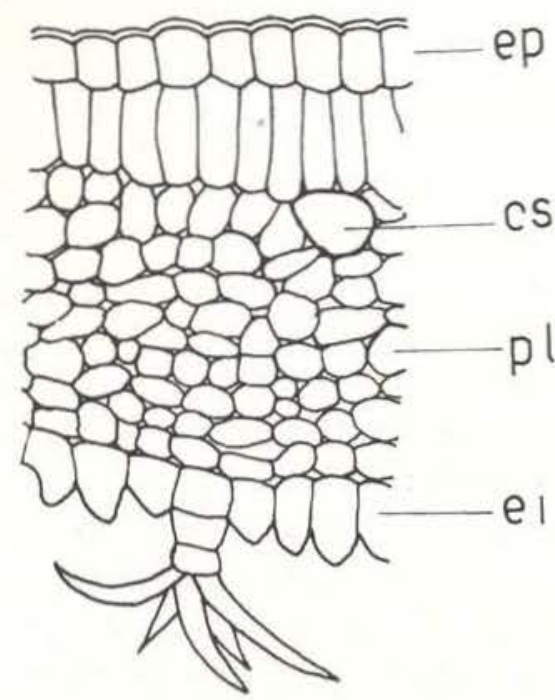

Fig. 5-Virola surinamensis Warb. - Corte transversal do mesófilo: ep, epiderme superior; es, células secretoras de óleo-tesina; ei, epiderme inferior com pelo pedunculado ramificado. Aumento 316X. (Cópia do desenho de Martin-Lavigne, 1909).

rede ondulada; a epiderme inferior, cujas célu las todas são distintamente papilosas, possui numerosíssimos pelos estrelados com o pedúnculo bicelular. Os estômatos, imersos na epiderme inferior e envolvidos por 4 a 5 células irregulares, têm sua observação bastante dificultaaa devido às papilas epidérmicas e à pilosidade

\section{ANATOMIA DA MADEIRA}

Estudos sobre a anatomia da madeira de ucuuba encontram-se principalmente em Martin-Lavigne (1909), Stone (1922), Garratt (1933). Machado (1949), Mainieri (1958a, 1958b, 1962), Record \& Hess (1949), Lindeman \& Mennega (1963), Metcalfe \& Chalk (1965) e Loureiro \& Silva (1968).

A descrição da estrutura microscópica dâ ucuuba de várzea (Virola surinamensis) segue abaixo, baseada principalmente nos estudos de Martin-Lavigne (1909). (Figs. 6 e 7)

Vasos solitários ou geminados, frequentemente multiplos de 3 , poucos a pouco numerosos, geralmente entre 10 a 15 por $\mathrm{mm}^{2}$, médios, em geral de 70 a 150 micra de diâmetro, ovais ou arredondados, parede dos vasos de 3 a 4 micra de espessura; pontuações intervasculares simples, ovóides ou lineares e espaçadas, médias alternas, abertura inclusa e curta. Raios dis- 
postos irregularmente, geralmente bisseriados, raramente uni - ou trisseriados, heterocelulares (Kribs IIB), de muito baixos a baixos, entre 300 a 1000 micra de altura de 30 a 40 micra de

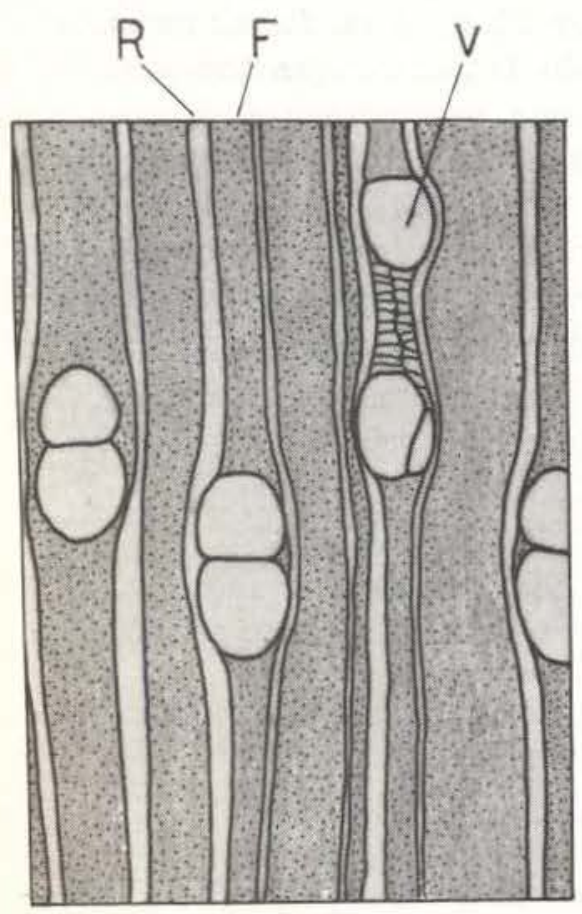

Fig. 6 -Virola surinamensis (Rol.) Warb - Corte transversal esquemático da madeira

$F$, fibras; $R$, raios; $V$, vasos. Aumento $50 \mathrm{X}$.

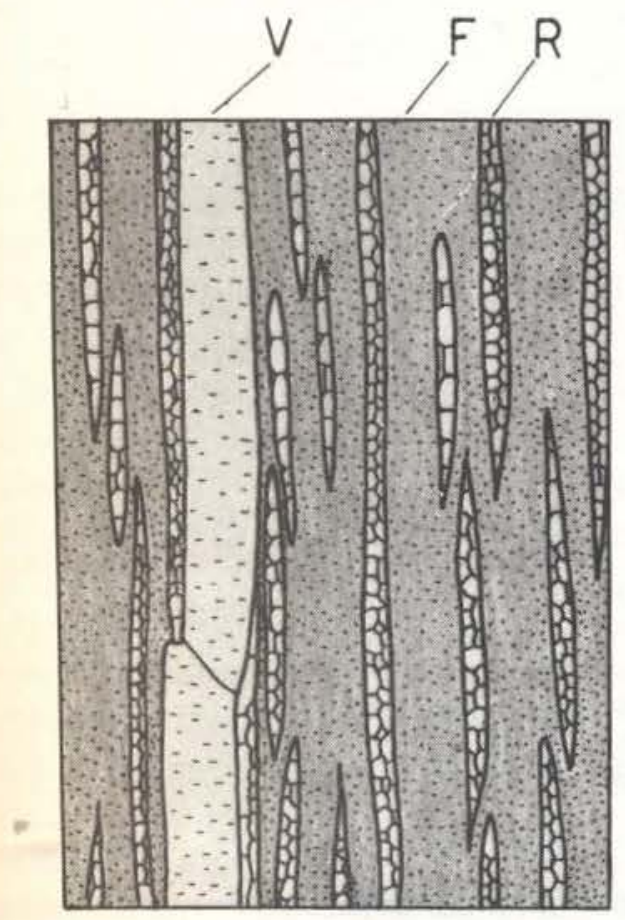

Fig. 7 - Virola surinamensis (Rol.) Warb. - Corte tangencial: $F$, fibras; $R$, raios: $V$, vasos. Aumento $50 \mathrm{X}$ espessura, formando em corte tangencial fusos longos e irregulares terminados nos extremos por 1,2 ou 3 células um pouco maiores que as outras, a terminal um pouco mais alongada; 10 a 12 raios por $\mathrm{mm}$, separadas por intervalos variáveis de 50 a 120 micra; pontuaçōes rádio-vasculares grandes, alongadas ou arredondadas, simplificadas ou com bordos estreitos aparen tes; óleo-resina abundante. Parênquima muito escasso, reduzido apenas ao paratraqueal com algumas células em contato com os poros. Fi. bras arrumadas radialmente, de parede pouco espessa. lumen grande, de 1300 a 1600 micra de compr. e 10 a 20 de diâmetro, representando $66 \%$ da massa de madeira. Camadas de crescimento pouco distintas, demarcadas especialmente por faixas de fibras de parede espessa.

\section{APLICAÇõES DA UCUUBA}

Desde os primórdios do descobrimento do Brasil já se dava valor à ucuuba como planta útil da flora brasileira sob a denominaçāo indígena de "hiboucouhu" e "ucuuba". Os índios sempre levavam consigo nas suas incursões guerreiras e viagens um cachimbo cheio de sebo dessas sementes-óleo graxo - para aplicação em ferimentos ocasionais e principalmente para fecharem os buracos provenientes da extração de bichos de pé (Tunga penetrans L), muito vulgar naquela época. Cita Le Cointe (1947), que, devido ao alto teor do óleo nas sementes, os aborígenas têm por hábito empregá-las como vela, para isso enfiando algumas delas em talo de palmeira inajé Maximiliana regia Mart.). Segundo Pesce (1941) os indios costumam fabricar velas por processo muito rudimentar de extraçăo da gor. dura de suas sementes. Dão luz muito intensa e queimam produzindo pouco fumaça e desprendendo cheiro agradável.

Certas espécies afins à ucuuba de várzea (Virola surinamensis), que se sabem ocorrerem com relativa abundância em todo o vale amazônico, nas margens alagáveis de rios, igapós e várzeas são principalmente a $V$. elongata $(=V$. cuspidata), $V$. carinata e $V$. pavonis. Até agora não se conhece referência alguma sôbre o seu emprêgo comercial na região, muito 
embora nada se contradiga que não pudessem ser utilizadas de algum modo como sucedânees da espécie em questão.

\section{USO MEDICINAL}

Algumas espécies de ucuuba ou bicuiba têm fama popular de curar reumatismo, artritismo geral, cólicas, dispepsias e erisipelas. Segundo Le Cointe (1947), o cozimento da casca é empregado para fazer assepsias de feridas e ajudar a sua cicatrização. A seiva junto com o cozimento de camapu (Physalis sp.), usa-se nas hemorróides em chumaço de algodão.

Schultes (1954) e Prance (1970) destacam o uso do rapé extraido da casca de algumas espécies com poderes alucinogênicos há muito usado pelos índios da região amazônica sob o nome de "paricá". Estudos químicos recentes segundo Schultes (1971) e Agurell et al. (1969), demonstraram que nesses rapés há grandes concentrações da 5-metoxi-N, $\mathrm{N}$-dimetiltriptamina, com quantidade menor de outras triptaminas, todas poderosamente alucinogênicas.

\section{O SEBO DA UCUUBA}

Desde os tempos pré-colombianos o sebo de ucuuba já tinha o seu emprêgo firmado para diversos fins, extraido de diversas espécies de Virola. Embora muitas dessas espécies apre sentem uma gordura semelhante no aspecto e constantes químicas, as mais conhecidas e mais exploradas comercialmente são a ucuuba de várzea (Virola surinamensis (Rol) Warb.) e a ucuuba vermelha (Virola sebifera Aubl.), especialmente a primieira pela sua grande abundância no estuário amazônico (municípios paraenses de Cametá, Igarapé-miri, Abaeté, Muaná e em toda a regiáo das ilhas). onde os frutos são colhidos de forma muito rudimentar da superfície d'água nas regiões inundáveis, juntamente com muitas outras oleaginosas.

Muito embora ainda hoje o sebo de ucuuba figure entre os principais produtos da indústria extrativa da Amazônia, com largo emprêgo regional na confecção de sabões $\epsilon$ velas, o seu processo de fabrico ainda deixa muito a desejar devido ao arcaismo com que opera a maioria das indústrias regionais. A sua comerciali- zação poderá ser largamente ampliada se todos os seus subprodutos forem racionalmente explorados. Do sebo se podem extrair alguns subprodutos altamente rentáveis como a trimiristina e o ácido mirístico. A trimiristina, que até hoje só se extrai da noz moscada, é um triglicérido de aita cotação comercial de emprêgo importante nas indústrias de cosméticos, perfumaria e confeitaria. Dele se pode obter, segundo Pinto (1951), até cerca de $64,7 \%$ do referido triglicérido, muito embora o rendimento nas condiçōes normais, conforme o mencionado técnico, possa ser na realidade de 35 à $40 \%$.

O peso de uma semente varia de 1,3 a $1,8 \mathrm{~g}$. constituindo-se de 12 a $19 \%$ de casca e 81 a $88 \%$ de amêndoa. Apanhado do chão seco a sua umidade é de 20 a $25 \%$.

A composição centesimal da amêndoa, de acordo com Völcher, citado por Warburg (1897) e Pinto (1951), é a seguinte:

\begin{tabular}{|c|c|c|c|}
\hline \multirow{6}{*}{$\begin{array}{l}\text { Agua } \\
\text { Gordura } \\
\text { Substâncias nitrogen: das } \\
\text { Açúcar, amido e fibras } \\
\quad \text { solúveis }\end{array}$} & \multirow{2}{*}{ Völcher } & \multicolumn{2}{|c|}{ Pinto } \\
\hline & & $\begin{array}{l}\text { Amêndoa } \\
\text { úmida }\end{array}$ & $\begin{array}{l}\text { Amêndoa } \\
\text { seca }\end{array}$ \\
\hline & $4,74 \%$ & $9,3 \%$ & - \\
\hline & 60,55 & 60,8 & $67,0 \%$ \\
\hline & 5,75 & 10,5 & 11,6 \\
\hline & 20,14 & 17,4 & 19,3 \\
\hline Celulose & 7,13 & - & - \\
\hline Cinzas & 1,69 & 2,0 & 2,1 \\
\hline & $100,00 \%$ & $100,0 \%$ & $100,0 \%$ \\
\hline
\end{tabular}

Cousiderando a existência de ácidos sob a forma de triglicéridos, Pinto (1951) dá a seguinte composiçã̃o centesimal para o sebo de ucuu-ba :

$\begin{array}{cc}\text { Ácidos graxos saturados } & \% \\ \text { Cáprico } & 0,6 \\ \text { Láurico } & 11,4 \\ \text { Mirístico } & 61.3 \\ \text { Palmítico } & 2,7 \\ \text { Esteárico } & 0,8 \\ \text { Ãcidos insaturados } & 6,7 \\ \quad \text { Oleico } & 4,5 \\ \text { Linoleico } & 4,4 \\ \text { Substância resinosa } & 2,5 \\ \text { Insaponificáveis } & 5,1 \\ \text { Radical glicérico } & 100,0 \% \\ & \end{array}$

Uma diminuta quantidade de óleo essencial, oleoso e de cor amarelada em contato com o ar também se pods encontrar no mesmo material. 
As suas propriedades físico-químicas, conforme dados apresentados por Pesce (1941), Le
Cointe (1924) e Pinto (1951) constam do Quadro II abaixo.

\section{QUADRO II}

Resultado da análise físico-química do sebo de ucuuba (Virola surinamensis (Rol.) Warb.) segundo dados de Pesce (1941), Le Cointe (1924) e Pinto (1951).

\begin{tabular}{|c|c|c|c|c|}
\hline Determinaçöes & $\begin{array}{l}\text { Químico } \\
\text { italiano }\end{array}$ & R. Bolton & Le Cointe & Pinto \\
\hline Ponto de fusão inicial & $40^{\circ} \mathrm{C}$ & $41,7 \circ$ & $40^{\circ}$ & $41,9^{\circ}$ \\
\hline$" \quad " \quad "$ completa & $43,5^{\circ}$ & $45^{\circ}$ & - & $44,0^{\circ}$ \\
\hline " $\quad " \quad$ dos ácidos gordos inicial & $40^{\circ}$ & - & - & - \\
\hline " " " dos ácidos gordos completa & $45^{\circ}$ & - & $45^{\circ}$ & - \\
\hline " " " solidificaçäo & $40^{\circ}$ & $40^{\circ}$ & $40^{\circ}$ & $33,0^{\circ}$ \\
\hline Densidade a $15^{\circ}$ & 0,9390 & - & - & $\ldots$ \\
\hline Indice de saponificação & 226,9 & 220,3 & $219-221$ & 217,2 \\
\hline$n \quad n$ iodo & 12,75 & 14,8 & $9-14$ & 16,9 \\
\hline " " Reichert Messl. & 14 & - & - & 1,1 \\
\hline " Polenske & 5,6 & - & - & - \\
\hline " " refração (Zeiss a $40^{\circ}$ ) & 53 & 50,9 & - & - \\
\hline$" n \quad$ (Abbé a 100 C) & - & - & - & 1,4342 \\
\hline " & 50 & $\overline{12 \%}$ & $\overline{750}$ & $\overline{107}$ \\
\hline $\begin{array}{l}\text { Ácidos gordos livres (oleico) } \\
n\end{array}$ & $17,50 \%$ & $12 \%$ & $17,5 \%$ & $\begin{array}{l}10,7 \\
88 \%\end{array}$ \\
\hline Matéria insaponificável & $3 \%$ & $3,16 \%$ & $3,2 \%$ & $2,5 \%$ \\
\hline Grau termossulfúrico (Tortelli) & 28 & - & - & $\overline{s i n}$ \\
\hline Radical glicérico & - & - & - & $5,1 \%$ \\
\hline
\end{tabular}

Para obtenção de uma gordura de boa qualidade, sem acidez livre elevada, é essencial que a semente seja conservada com $7-8 \%$ de umidade, de acôrdo com observações de Pinto (1951) Teor mais elevado pode deteriorar a semente devido à ação químico-biológica. O sebo obtido de sementes bem conservadas é de côr amarelo-clara e o de sementes velhas, bastante escuro. A gordura fresca com pouca acidez tem cheiro agradável e gosto aromático. O ponto de solidificação baixa indica que a gordura se mantém sólida à temperatura ambiente. É solúvel em ácido sulfúrico concentrado, apresentando intensa coloração vermelha de fucsina. que desaparece algumas horas depois. Segun. do Pinto (1951), dentre os solventes mais conhe cidos, o melhor para a separação da gordura de ucuuba é o éter sulfúrico, muito embora em escala industrial os mais indicados tossem o éter de petróleo, benzina e o bissulfeto de carbono. Com o benzeno, o rendimento pode chegar a $77,5 \%$.

0 rendimento de gordura na amêndoa seca, extraida com éter sulfúrico, é de $67 \%$, ou seja $55 \%$ de peso total da semente seca.

São os seguintes os emprêgos tecnológi- cos que se poderiam dar à matéria graxa da ucuuba de acôrdo com os estudos físico-químicos apresentados no Quadro II acima :

a) confecção de sabões em substituição ao sebo animal em mistura com outros óleos como o de andiroba (Carapa guianensis Aubl.) e babaçu (Orbigna speciosa (Mart.) B. Rodr.) para reduzir a sua dureza e côr escura.

b) fabricação de velas, devidio ao elevado teor em ácidos graxos sólidos como o mirístico, palmítico e esteárico;

c) fabrico altamente rentável de trimiris. tina e ácido mirístico para emprêgo nas indústrias de cosméticos, perfumaria e confeitaria;

d) fabrico de cera para assoalho em mistura com outras gorduras como sucedânea do sebo de Bornéu;

e) produção de manteiga vegetal em substituição à manteiga de cacau pelo possível isolamento da substância resinosa.

\section{A torta de ucuuba}

Tortas resultantes da boa prensagem e extração por solventes foram analisadas por Guimarães et al. (1970). Os resultados dessas análises estão transcritos no Quadro III abaixo : 


\section{QUADRO III}

Resultados da análise da torta de ucuuba (Virola surinamensis (Rol.) Warb.) obtida com. parativamente pelos métodos de prensagens e extração por solventes. Dados tirados de Guimarães et al. (1970).

\begin{tabular}{|c|c|c|}
\hline Determinacão & \multicolumn{2}{|c|}{$\begin{array}{c}\text { Método dé preparo } \\
\text { da torta }\end{array}$} \\
\hline & Prensagem $(\%)$ & Solvente $(\%)$ \\
\hline Voláteis a $105^{\circ} \mathrm{C}$ & 4,46 & 4,79 \\
\hline Resíduo mineral fixo & 5,84 & 6,28 \\
\hline Nitrogêneo & 3,34 & 3,59 \\
\hline Proteínas brutas & 20,95 & 22,43 \\
\hline Extrato etéreo & 8,00 & 1,00 \\
\hline Extrato nấo nitrogenado & 26,84 & 29,01 \\
\hline Fibras brutas & 33,91 & 36,49 \\
\hline $\mathrm{CaO}$ & 1,04 & 1,11 \\
\hline $\mathrm{P}_{2} \mathrm{O}_{5}$ & 1,13 & 1,21 \\
\hline
\end{tabular}

Conforme análise acima a torta poderia ser usada para alimentação do gado ou para emprego como adubo em mistura com cinzas.

Bem preparada a torta é amarelo-clara, sem resina e inteiramente livre de gorduras, toman. do bom aspecto ao paladar do gado. Devido ao elevado teor de fibras, que poderia impedir a sua aceitação pelo animal, por ser de difícil digestão, a mesma deveria ser melhorada com adição de outras tortas.

\section{MADEIRA}

A ucuuba branca da várzea nos últimos anos tem ccupado o primeiro lugar na Amazênia, no volume de exportação de madeiras, especialmente beneficiadas em folheados e compensados. Começou a sua valorização em 1945 no Suriname e apenas em 1958 na Amazônia Brasileira, apresentando depois um rítmo sempre crescente de expansão de sua exportaçăo em forma de madeira serrada e desenrolada.

\section{Caracteristicas gerais}

O alburno e o cerne quando recém-cortados são quase da mesma cor, cremes ou pardos. tornando-se assim quase indistinguiveis. Ao secar o exposto à luz, o cerne fica mais escuro, variando do rosado ao castanho avermelhado in. tenso. O lustre é baixo. É inodora e insípida quando seca. A grã é regular e a textura, grosseira.

O peso específico médio é 0,60 , variando entre 550 a $650 \mathrm{~kg}$ por metro cúbico. Seca-se facilmente sem empenar ou fender-se. Secagens rápidas, no entanto, podem provocar ligeiros empenos e endurecimento superficial. Devido à baixa densidade, é fácil de trabalhar. Segundo Record \& Hess (1949), não há dificuldade alguma em se cortar a madeira à mão ou com serra mecânica e em se obter boa superficie com garlopa e plainadeira, tanto no sentido lon. gitudinal como no normal à fibra. Com relativa facilidade fazem-se furos perfeitos com punção, verruma, pua e broca sem o perigo de racnar, o mesmo acontecendo com pregos e parafusos. Sem aırıculaade pode-se sambra-ıa a maquina e entaına-ıa vem com goiva e tormao. rode-se tornea-la satısiatoriamente, muito em. bora as fibras tendam a romper-se ligeiramente. Aceita bom acabamento. Absorve bem a cola, pode-se pintá-la sem dificuldade $\epsilon$ receber verniz e polimento razoavelmente. Quando manufaturada, não empena nem se fende. Geralmente não apresenta nós nem outros defeitos em sua superficie.

\section{DURABILIDADE}

Segundo Bertin(1920) a madeira é de baixa durabilidade, não suportando mais que 3 anos quando exposta ao tempo. Segundo Wangaard \& al. (1954), madeiras de ucuuba da várzea submetidas à prova com culturas puras dos fungos Polyporus versicolor e Poria montícola, provaram não ser duráveis (decomposição de 62 a $83 \%$ em 4 meses de teste de laboratório). A madeira é também facilmente atacada por vários insetos xilófagos, necessitando assim que suas toras sejam tratadas imediatamente com preservativos ou retiradas logo do local de ex- 
tração, serradas ou estocadas dentro d'água até que sejam desdobradas. A ucuuba mesmo depois de seca é tida como susceptavel a ataque de certos bezouros, necessitando de cuidados especiais ou vigilància constante, se forem armazenadas.

\section{Caracteristicas físico-mecânicas}

Estudos neste sentido foram feitos por Wangaard \& al. (1954), I.P.T. (1956) e Weinbaum (1937). Os resultados dos ensaios realizados pelos dois primeiros estão incluidos nos Quadros IV e V abaixo.

\section{QUADRO IV}

Propriedades físico-mecânicas da madeira de ucuuba da várzea (Virola surinamensis Warb.) segundo testes realizados pelo I.P.T. (1956).

\section{CARACTERISTICAS FISICAS}

Peso específico aparente (a $15 \%$ de umidade)

$0,48 \mathrm{~g} / \mathrm{cm}^{3}$

Retratibilidade (contraçôes em \%):

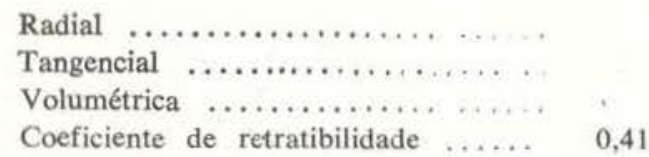

\section{CARACTERISTICAS MECÂNICAS}

Compressăo axial :

Limite de resistência $\left(\mathrm{Kg} / \mathrm{cm}^{2}\right)$

Coeficiente de influência da umidade $(\%), \ldots \ldots \ldots \ldots \ldots \ldots \ldots \ldots \ldots \ldots \ldots \ldots \ldots \ldots \ldots \ldots \ldots \ldots \ldots \ldots, 2$

a $15 \%$ da umidade $\ldots \ldots \ldots \ldots \ldots \ldots \ldots \ldots \ldots \ldots \ldots \ldots \ldots \ldots \ldots \ldots \ldots \ldots \ldots \ldots \ldots \ldots, 4$ $100 \mathrm{D}$

Flexão estática

Limite de resistência $\left(\mathrm{Kg} / \mathrm{cm}^{2}\right)$

Relaçāo L

Módulo de elasticidade $\left(\mathrm{Kg} / \mathrm{cm}^{2}\right)$

$\begin{array}{lll}\text { Compressão } \ldots \ldots \ldots \ldots \ldots \ldots & \begin{array}{l}\text { Módulo } \\ \text { Limite de proporcionalidade } \\ \text { Flexão } \ldots \ldots \ldots \ldots \ldots \ldots \ldots \ldots\end{array} & \begin{array}{l}\text { Módulo } \\ \text { Limite de proporcionalidade }\end{array} \\ 141\end{array}$

Choque (madeira seca ao ar)

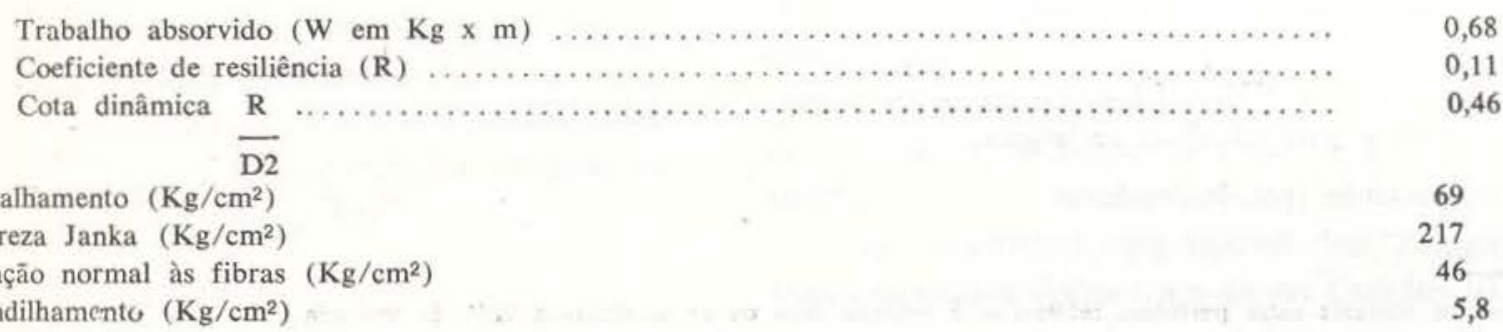




\section{QUADRO V}

Propriedades físico-mecânicas da ucuuba de várzea (Virola surinamensis Warb.) segundo testes de Wangaard \& al. (1954).

\section{CARACTERISTICAS FISICAS}

Peso específico :

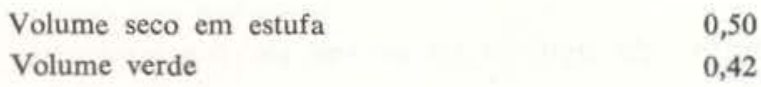

Conteúdo de umidade:

Madeira verde $\quad 93,8$

Madeira seca ao ar (12\% de umidade) $\quad 11,4$

Retratibilidade. (\%):

$\begin{array}{lr}\text { Radial } & 5,3 \\ \text { Tangencial } & 12,4 \\ \text { Longitudinal } & 0,0 \\ \text { Volumétrica } & 17,6\end{array}$

\section{CARACTERISTICAS MECÂNICAS}

Flexão estática :

Tensão da fibra a limite da proporcionalidade (lb./pol. $\left.{ }^{2}\right)$

$3580(6900)$.

Tensão de rutura $\left(\mathrm{lb} . / \mathrm{pol} .^{2}\right)$

Módulo de elasticidade (1000 lb./pol.2)

Trabalho a limite da proporcionalidade (poi. - lb./pol. ${ }^{2}$ )

$5600(10950)$ का

$1640(2040)$ *

Trabalho a carga máxima ( $\mathrm{pol},-\mathrm{lb}, / \mathrm{pol},{ }^{2}$ )

Compressäo axial :

Tensão da fibra a limite da proporcionalidade ( $\mathrm{lb} . / \mathrm{pol} .{ }^{2}$ )

Resistência máxima à compressão (1b./pol .2)

Módulo de elasticidade (1000 lb./pol.2)

Dureza :
Extremidade (lb.)
$430(560) \times$
Lado (lb.)
$320(510) *$

Compressāo normal à fibra (tensão a limite de pioporc.) (lb./pol.2)

$200(270)$ के

Tensão normal à fibra (lb./pol.2)

$260(360)^{*}$

Cizalhamento (lb./pol. $\left.{ }^{2}\right)$

$729(980)=$

Fendilhamento (lb./pol. de largura)

$180(200) *$

60,6

(4) - Os nûmeros entre parêntese referem-se à madeira sềca oo ar, ajustados a $12 \%$ de umidade. 


\section{COMENTÁRIOS}

Segundo os resultados do erisaio apresentados por Wangaard \& al. (1954) em comparação com outras madeiras medianamente leves, a ucuuba verde é inferior em todas as propriedades de resistência, porém sua rigidez é consideravelmente elevada. Em resistência à com. pressão e tensão normal à fibra, é particular. mente deficiente. A ucuuba é muito semelhante ao "choupo amarelo" (Liriodendron tulipifera) dos Éstados Unidos, divergindo, quando no estado verde, apenas na maior rigidez da primeira, e na evidente superioridade da segunda na compressão e tensão normal à fibra. Ela supe. ra o mogno (Swietenia macrophylla) em muitas propriedades, exceto no módulo de elasticidade.

A ucuuba seca ao ar melhora bastante todas suas propriedades. Se comparada com outras espécies de igual densidade, passa a uma posição mais favorável do que a madeira verde. Além da rigidez consideravelmente elevada, ela é superior em trabalho à carga máxima e muito próxima à média antecipada na base de seu peso específico em resistência à flexão, resistência à compressão, tensão normal à fibra e cizalhamento. Em outros aspectos é inferior.

Seca ao ar, é semelhante ao "choupo amarelo" em muitos aspectos, excedendo a esta por uma margem relativa pequená nas maiores pro. priedades de flexão estática, exceto na rigidez. Nesta propriedade, a superioridade mostrada pela ucuuba no estado verde foi mantida. A superioridade do mogno sobre a ucuuba é bastante evidente nos valores de dureza, compressão e tensão transversa, cizalhamento e fendilhamento, embora a ucuuba mantenha certa vantagem na rigidez mostrada anteriormente para o estado verde. Mostra retratibilidade excepcionalmente elevada, especialmente na direçãc tangencial.

Quanto à secagem ao ar livre, Wangaard \& al. (1954) demonstra em testes realizados nas condições climáticas dos Estados Unidos (New Haven, Connecticut) que a ucuuba seca-se rápido, apresentando apenas ligeiro empeno e en-

(*) - "yellow poplar". durecimento superficial resultante da secagem rápida. Garratt (1933) assinala que ela è de dificil acabamento porque a madeira fende-se muitíssimo, especialmente no sentido radial, soltando tiras e expondo o desenho de modo em geral fora do comum.

\section{EMPRÊGOS DA MADEIRA}

Baseado nos testes físico-mecânicos, a ucuuba se presta especialmente para móveis trabalhos de interiores, construçäo de moinho e produção de laminados para compensado. Outras aplicações que se poderiam recomendar seriam para urna funerária, táboas, caixas e palitos de fósforos, carpintaria em geral, caixas de embalagem e tanoaria.

\section{Celulose e papel}

A Amazônia possui um repositório imenso de madeiras que se poderiam utilizar para produçäo de celulose e papel. Só depois de uns anos para cá, com as metas prioritárias do Govêrno de valorização do vale amazônico, é que esse potencial tem sido devidamente avaliado e estudado.

Os primeiros estud s regionais concretos que se conhecem sobre a possibilidade de aproveitamento de madeiras tropicais em mistura para produção de papel de imprensa, em que a ucuuba de várzea foi um dos principais componentes, foram feitos pela Companhia Isorel da França e, posteriormente, pela Companhia Klabin do Paraná, contorme informaçōes de Pires (1959).

Visando mais especificamente ao aproveitamento racional da ucuuba de várzea para produção de celulose e papel, o trabalho mais específico que se conhece é o que realizou recentemente Melo \& al. (1970 e 1971b.). Para o possível aproveitamento de uma espécie afim, a ucuuba de terra firme (Virola melinonii iBen.) A. C. Smith), estudo semelhante foi promovido há pouco tempo pela Superintendência do Desenvolvimento da Amazônia, tendo os resultados deste estudo sido publicados no relatório intitulado "Estudo de viabilidade de exploração industrial da mata amazônica ná região de CuruáUna".

Os resultados dos testes das 2 espécies supra-referidas encontram-se no Quadro VI. 


\section{QUADRO VI}

Resultados dos testes efetuados com resíduos de madeira da ucuuba da várzea (Virola surinamensis Warb.) e madeira de ucuuba de terra firme (Virola melinonii A.C. Smith) para fins de produção de celulose e papel. (De Melo et aı, (1971b) e SUDAM).

\begin{tabular}{|c|c|c|c|c|c|c|c|c|c|c|c|c|c|c|c|}
\hline \multirow[b]{2}{*}{ ESPÉCIE } & \multirow{2}{*}{ 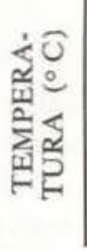 } & \multicolumn{5}{|c|}{ COZIMENTO } & \multicolumn{5}{|c|}{ RESISTENCIA A $45^{\circ}$ S.R. } & \multicolumn{4}{|c|}{ FIBRAS (Valor médio em $\mathrm{mm}$ ) } \\
\hline & & 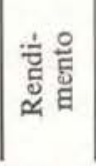 & ஃ. & 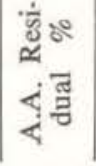 & 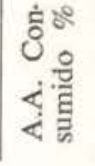 & 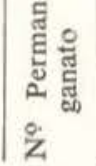 & 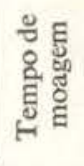 & 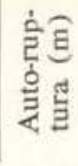 & 을 & 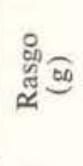 & 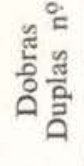 & है. & बू. & छّ & हुँّ \\
\hline Ucuúba da várzea & 170 & 48,44 & 1,11 & $1,42^{*}$ & 12 & 17,75 & 30 & 7600 & $5,10^{*}$ & 117 & 1700 & 1,5010 & $0,0340 \mid$ & 0,0212 & ' 0,0064 \\
\hline $\begin{array}{l}\text { Ucuúba da terra } \\
\text { firme }\end{array}$ & 170 & 49,29 & 0,70 & $1,76^{*}$ & 18,30 & - & 30 & 6800 & $57,5 c^{* *}$ & 94 & - & 1,279 & 0,0196 & 一 & 一 \\
\hline
\end{tabular}

$$
\text { A.A. - Alcali ativo. }
$$

(*) - Para a ucuúba de várzea o cáleulo de álcail ativo residual é dado em $\%$ e para a ucuúba de terra firme, em $g / 1$.

(*) - Para a ucuúba de várzea o cálculo de estouro é dodo em $\mathrm{Kg} / \mathrm{cm} 2$ e para a ucuúba de terra firme, em lb./pol.2 paro $100 \mathrm{~g} . / \mathrm{m} 2$.

\section{COMENTÁRTOS}

Embora em rendimento de celulose a ucuuba de terra firme tenha sido um tanto superior ao da ucuuba branca de várzea, nuta-se no Quadro VI que esta é em quase tudo melhor que a primeira. Nota-se também que os dados comparativos foram baseados utilizando matéria prima diferente, a primeira apenas madeira e a segunda só resíduos das indústrias de laminados. Segundo Melo \& al. (1970 e 1971b), a madeira propriamente dita de ucuuba da várzea apresenta características de resistência ao estouro, auto-rutura e dobras duplas signitivamen. te bem melhores que as do resíduo analisado e exposto no Quadro VI, e surpreendentemente maiores que as que se conhecem para o guapuruvu (Schyzolobium parahybum Killip), Eucalipius saligna e outras folhosas.

A análise realizada com o resíduo indica que a ucuuba de várzea pode ser utilizada como fonte de celulose, especialmente se, propositalmente, for integrada de restos de madeira de várias idades, resultando dai papeıs Kraft de boa qualidade.
A grande vantagem do emprêgo do resíduo sobre a madeira de ucuuba para a produçäo de celulose é indiscutível, não só pelo menor pre. co aquisitivo da matéria prima como pelo grande benefício que disso obviamente adviria no aproveitamento racional de uma madeira em franca valorização.

\section{DIMENSIONAMENTO DAS FLBRAS}

Os resultados das medições micrométricas das fibras da ucuuba de várzea constam do Quadro VII abaixo. Com base nessas mesmas medições, a distribuição percentual de suas fibras. tendo em vista seu possível aproveitamento para produção de papel e celulose, è a seguinte :

Comprimento :

$$
\begin{aligned}
& \text { curtas }-76 \% \\
& \text { longas }-24 \%
\end{aligned}
$$

Largura :

$$
\begin{aligned}
& \text { estreitas }-56 \% \\
& \text { médias }-42 \% \\
& \text { largas }-2 \%
\end{aligned}
$$




\section{QUADRO VII}

Ficha biométrica das fibras de ucuuba de várzea (Virola surinamensis (Rol.) Warb.). Dados extraídos de Melo et al. (1971b).

\begin{tabular}{|c|c|c|c|c|c|}
\hline ESPECIFICAÇÁO & $\begin{array}{l}\text { Máximo } \\
\text { (micra) }\end{array}$ & $\begin{array}{c}\text { Médio } \\
\text { (micra) }\end{array}$ & $\begin{array}{l}\text { Mínimo } \\
\text { (micra) }\end{array}$ & $\begin{array}{l}\text { Desvio } \\
\text { padraão }\end{array}$ & C. V. \\
\hline Comprimento & 1785 & 1340 & 1035 & \pm 418 & 31,23 \\
\hline Largura & 45 & 32 & 15 & \pm 6 & 18,69 \\
\hline Lumen & 32 & 15 & 4 & \pm 7 & 45,00 \\
\hline Espessura da parede & - & 8.5 & - & - & - \\
\hline Relação compr. /larg. & - & 42 & - & - & 一 \\
\hline $\begin{array}{l}\text { Relação lumen/larg. } \\
\text { (C.F.) }\end{array}$ & - & 0,47 & - & - & - \\
\hline
\end{tabular}

C.V. - Coeficiente de variação

C.F. - Coeficiente de flexibilidade

Os comprimentos das fibras de ucuuba são altamente desejáveis à produção de celulose. Confrontando com o guapuruvu, suas fibras têm comprimento e espessura das paredes maiores, embora de diâmetro menor. Em relação ao Eucaliptus saligna de 5 anos, apresentam maior coeficiente de flexibilidade e menor comprimento relativo, significando esses dados que o papel feito com ucuuba possui certa superioridade na resistência à tração (Auto-rutura) e me. nor resistência ao rasgo. sendo as paredes das fibras mais grossas que as do Eucaliptus embora de comprimento, diâmetro e lumen bem maiores. Admite Melo et al. 1971a.) que a espécie em questão poderá produzir papéis de maior comprimento de auto-rutura, embora de menor opacidade e, um tanto menos volumosos.

\section{ANÁLISES QUÍMICAS DA MADEIRA}

As análises químicas da madeira de ucuuba de várzea foram efetuadas por Melo et al. (1970 e 1971a.), estando os resultados dessas determinações no Quadro VIII a seguir.

\section{QUADRO VIII}

Resultados das análises químicas da ma. deira de ucuuba de várzea (Virola surinamensis (Rol.) Warb.). Dados tirados de Melo et al. (1970 e 1971a).

\section{L.}

Determinações

Resultados \%

\begin{tabular}{lr} 
Celulose (Cross \& Bevan) & 55,58 \\
Lignina & 20,68 \\
Pentosanas & 13,94 \\
Resíduo mineral fixo a $600^{\circ} \mathrm{C}$ (Mufra) & 1,19 \\
Solubilidades.: & \\
$\quad$ Água fria & 5,28 \\
$\quad$ Água quente & 5,44 \\
$\quad$ Álcool-Benzol & 2,65 \\
$\quad$ Hidróxido de Sódio a $1 \%$ & 17,32 \\
\hline
\end{tabular}

Com base nos dados analíticos acima, conclui-se que, quanto ao teor de celulose, a madeira de ucuuba se situa entre as melhores folhosas conhecidas do País, como o guapuruvu e o Eucaliptus saligna e que com ela é possivel a obtenção de papéis de resistência razoável, embora não brancos. 


\section{SUMMARY}

This work is a bibliographic revision of a very important economic tree known in Brasilian Amazo. nia as ucuuba de várzea (Virola surinamensis). Comments principally on its botanical, silvicultura] and tecnological aspects are here included.

\section{BIBLIOGRAFIA CITADA}

Agurell, S. ET ALII

1969 - Alkaloides in Certain Species of Virola and other South American Plants of Ethnopharmacologie Interest. Acta. Chem. Scand., 23(3).: 903-916.

AUBLET, F.

1775 - Histoire des Plantes de la Guiane Française. T. 2.: 904-908.

Bastos, A. DE Miranda

1929 - As madeiras da Amazônia na indústria do papel. Bol. Esc. Chimic. Ind., Belém, 1: 80-83.

BENA, P.

1960 - Essences forestières de Guyane. Paris, Bureau Agricole et Forestier Guayanais, Imprimerie Nationele. 488 p., $10 \mathrm{pl}$.

BERTIN, A.

1920 - Les bois de Guyana française et du Brésil. Paris, Mission d'Etudes Forestières, Ed. Emíle Larose. 318 p., 23 fig., 25 tab.

DuBois, J.

1967 - A floresta amazônica e sua utilização face aos princípios modernos de conservaçăo da nature. za. Atas do Simp. sôbre a Biote Amazonica, $?$ (Conservaçāo da natureza e recursos naturais): 115-146.

s.a. - Desenvolvimento de uma economia florestal na Amazônia; análise focalizando especialmente os aspectos silviculturais. Trad.: Helena Sousa. Publ. SUDAM, $36 \mathrm{p}$.

DUCKE, A.

1936 - Notes on the Myristicaceae of Amazonian Brazil with descriptions of new species. III. $J$. Wash. Acad. Sci., Washington, 26(6):253-264.

1938 - Plantes nouvelles ou peu connues de la Région Amazonienne. X. Archos. Inst. Biol. Veg., Rio de Janeiro, 4(1) : 1-64, 4 est.

1939 - Plantes nouvelles ou peu connues de la Région Amazonnienne (XI série). Arq. Serv. Flor., 1(1) : $1-40,12$ est

1945 - New forest trees and climbers of the Brazilen Amazon. Bol. Técn. Inst. Agron. Norte, Belém, $4: 8-12$.

Garratt, G. A.

1933 - Systematic anatomy of the woods of the Myristicaceae. Trop. Woods, New Haven, 35: 6-48, 9 fotos.
Guimarães, M. C. F. et ALII

1970 - Composição das tortas oleaginosas comercializadas no Pará. Inst. Pesq. Exp. Agrop. Norte; série: Tecnológica, 1(1) : 7-18.

Glerum, B. B .

1962 - Inventários da ocorrência da ucuúba (Virola surinamensis) na regiāo do baixo Tocantins. Trad. A. de Miranda Bastos. SPVEA. 19 p.

GLERUM, B. B. \& SMIT, G.

1965 - Inventário florestal total na região do CuruáUna. Inv. flor. da Amazônia, Belém, 7:1-51.

HeinsdiJK, D. \& Bastos, A. M.

1963 - Inventários florestais na Amazônia. Bol. Serv. flor., Rio de Janeiro, 6: 1-100.

HUTCHINSON, J.

1960 - The families of flowering plantes. Dicotyledons. 2, ed. Oxford, Clarendon Press., v. 1; $510 \mathrm{p}$.

Instituto de Pesquisas Tecnológicas (I.P.T.)

1956 - Tabelas de resultados obtidos para madeiras nacionais. Bol. Inst. Pesq. Tec., São Pau lo, 31: 29-30, 6 tab.

Le Cointe, $\mathrm{P}$.

1924 - Apontamentos sôbre as sementes oleaginosas, os bálsamos $e$ as resinas da floresta amazôni$c a$. Rio de Janeiro. 35 p.

1947 - Amazônia brasileira. III - Árvores e plantas úteis (Indígenas $e$ aclimatadas). 8. ed. São Paulo, Ed. Nacional. 506 p.

Lindemn, J. C. \& Mennega, A. M. W.

1963 - Bomemboek voor Suriname. Mededelingen von her Bot. Mus, en Herb. Rijksuniversiteit te Utrecht, 200 : 1-312; $96 \mathrm{pl}$., 96 fotos.

Loureiro, A. A. \& Sillya, M. F.

1968 - Catálogo das madeiras da Amazônia. Belém, SUDAM. 2 v.; 411 p.

MACHADO, O. X. B.

1949 - "Bicuiba" - "Virola bicuyba" (Schott) Warb. Rodriguésia, Rio de Janeiro, 24:53-78 2 est.

MAINIERE, C.

1958 - Identificação das principais madeiras de comércio no Brasil. Bol. Inst. Pesq. Tec., São Paulo, $46: 1-189,240$ fotos.

s.d. - Madeiras do Brasil. II. Publ. Inst. Pesq. Tec -, São Paulo, 573: 1-108.

1962 - Madeiras leves ca Amazônia empregadas em caixotaria; estudo anatômico macro e micros cópico. Publ. Inst. Pesq. Tec., Sảo Paulo, $686: 1-39,58$ fig.

MARTIN-LAVIGNE

1909 - Recherches sur les bois de le Guyane. Travaux Lab., Matière Med., Paris, 4(2) : 1-184.

MELo, C. F. M. ET ALII

1970 - A "ucuuba" como fonte de celulose para papel. O Papel, São Paulo, 31: 42-52. 
1971a- A "ucuúba" como fonte de celulose para papel. Inst. Pesq. Exp. Agrop. Norte; série: Tecnologia, Belém, 2(2): 1-29.

$197 \mathrm{lb}$ - Madeiras tropicais para reflorestamento, celulose e papel. Publ. Inst. Pesq. Exp. Agrop. Norte, série: Tecnologia, Belém, 2(1) : 1-75.

metcalfe, C. R. \& Chalk, L.

1965 - Anatomy of the Dicotyledons. Oxford, Clarendon Press. v. 2 : $725-1.500,167 \mathrm{fig}$.

MIILDE, R. DE \& GRoot, D. DE

1970 - Guyana. Inventary of a selected area in the north-west district. FAO. Technical Report $10: 1-49,2$ mapas.

Pesce, C,

1941 - Oleaginosas da Amazônia. Belém, Ed. Rev. Veterinária. $132 \mathrm{p}$.

PINTO, G. P.

1951 - Contribuição ao estudo químico do sebo de ucuúba. Bol. Téc. Inst. Agron. Norte, Belém, $23: 1-63$.

PIRES, J. M. \& Koury, H. M.

1959 - Estudo de um trecho de mata de várzea próxima de Belém. Bol. Téc. Inst. Agron. Norte. Belém, $36: 3-44$.

Porto, P. Campos

1936 - Plantas indígenas e exóticas provenientes da Amazônia, cultivadas no Jardim Botânico dc Rio de Janeiro. Rodriguésia, Rio de Janeiro 5: 93-157.

Prance, G. T.

1970 - Notes on the Use of Plant Hallucinogens in Amazonian Brazil. Econ. Bot, , Lancaster, Pa., 24(1): $62-68$.
RECORD, S. J. \& HESS, R. W.

1949 - Timbers of the New World. New Haven, Yale Univ. Press. 640 p.

SChultes, R. E.

1954 - A new narcotic snuff. from the northwest Amazon. Bot. Mus. Leafl. Harvard Univ., $16: 141-200$.

1971 - De plantis Toxicariis e mundo novo tropicale Mcommentationes. VIII. Miscellaneous notes on Myristicaccous plants of South America. Lloydia, 34(1): 61-78, 7 ilust. (separata).

Sмrтн, A. C.

1937 - The American species of Myristicaceae. Brittonia, New York, 2(5).: 393-510.

STONE, M. H.

1922 - Le bois utiles de la Guyane Française. An. Mus. Col. Marseille, 8(2): 1-14.

SUPERINTENDÊNCIA DE VALORIZAÇÃo DA AMAZÔNIA (SUDAM)

- Estudo da viabilidade da exploraçâo industrial da mate amazônica na regiâo do Curuá-Una (relatório). Belém, SUDAM. 120 p., 1 mapa.

WANGAARD, F. F. ET ALII

1954 - Properties and uses of Tropical Woods. Trop. Woods, New Haven, 99 : 1-187, 12 fig.

WARBURG, $\mathrm{O}$.

1897 - Monographie der Myristicaccen. Nova Acta Acad. Leop.Carol., 68: 1-680, pl. 1-25.

Weinbaum, $\mathrm{O}$.

1937 - Resultados de uma viagem de estudo de madeiras ao Pará e Amazonas. Bol. Min. Agricultura, Rio de Janeiro, 26(10-12): 21-32. 